Revista Brasileira de Farmacognosia Brazilian Journal of Pharmacognosy 22(2): 268-276, Mar./Apr. 2012

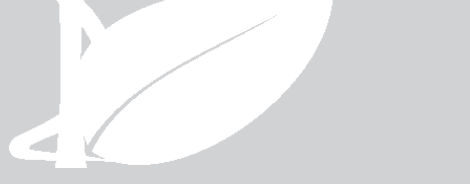

Article

Received 21 Nov 2010

Accepted 3 Jun 2011

Available online 2 Sep 2011

Keywords:

apoptosis

Lamiaceae

neobaicalein

Scutellaria litwinowii

wogonin

ISSN 0102-695X

http://dx.doi.org/10.1590/S0102-

$695 \times 2011005000161$

\section{Wogonin and neobaicalein from Scutellaria litwinowii roots are apoptotic for HeLa cells}

\author{
Zahra Tayarani-Najarani, ${ }^{1}$ Javad Asili, ${ }^{2}$ Heydar Parsaee, ${ }^{1}$ Seyed \\ Hadi Mousavi, ${ }^{1}$ Naser Vadati Mashhadian, ${ }^{3}$ Alireza Mirzaee, ${ }^{2}$ \\ Seyed Ahmad Emami ${ }^{* 2}$
}

\author{
${ }^{1}$ Pharmacological Research Centre of Medicinal Plants, School of Medicine, \\ Mashhad, University of Medical Sciences, Mashhad, Iran, \\ ${ }^{2}$ Department of Pharmacognosy, School of Pharmacy, Mashhad, University of \\ Medical Sciences, Mashhad, Iran, \\ ${ }^{3}$ Medical Toxicology Research Center, Mashhad, University of Medical Sciences, \\ Mashhad, Iran.
}

\begin{abstract}
Chemical investigation on the $\mathrm{CH}_{2} \mathrm{Cl}_{2}$ fraction of the Scutellaria litwinowii Bornm. \& Sint., Lamiaceace, root extract for the first time resulted in the isolation of wogonin, and neobaicalein. These compounds were evaluated for their cytotoxicity towards HeLa cell lines and lymphocytes. Meanwhile, the role of apoptosis was explored in this toxicity. The cells were cultured in RPMI medium and incubated with different concentrations of isolated flavonoids. Cell viability was quantified by MTS assay. Apoptotic cells were determined using propidium iodide staining of DNA fragmentation by flow cytometry (sub-G1peak). Wogonin, and neobaicalein inhibited the growth of malignant cells in a dose-dependent manner. The IC50 values of 46.62 and $79.34 \mu \mathrm{M}$ were, respectively, found for neobaicalein and wogonin against HeLa cells after $48 \mathrm{~h}$ of treatment. Neobaicalein induced a sub-G1 peak in the flow cytometry histogram of treated cells compared to control cells indicating that apoptotic cell death is involved in neobaicalein toxicity. Neobaicalein exerts cytotoxic and pro-apoptotic effects in HeLa cell lines and could be considered as a potential chemotherapeutic agent in cancer treatment.
\end{abstract}

\section{Introduction}

Scutellaria, Lamiaceae, is a genus of about 300 species of plants (Mabberley, 1993) and has been used as traditional medicine in China, India, Korea, Japan, Europe and North America (Shang et al., 2010). Scutellaria spp. possesses effective anticancer activity and this property is due to some flavones such as baicalin, baicalein and wogonin (Li-Weber, 2009). Scutellaria extracts are not only cytostatic but also cytotoxic in vitro and in vivo (Scheck et al., 2006; Shang et al., 2010).

Recent pharmacologic researches have confirmed that total extracts or flavonoids of the genus Scutellaria possess anti-lipoperoxidation, anti-platelet, antiinflammatory, antitumor, hepatoprotective, antioxidant, antibacterial and antiviral activities (Ye et al., 2004; Parajuli et al., 2009; Zhang et al., 2006; Burnett et al., 2007; Sonoda et al., 2004). In general, flavonoids are the most crucial class of compounds that have been isolated from several species of Scutellaria (Malikov \& Yuldashev, 2002). However, only a handful of the Scutellaria species have been studied for potential anticancer activity in the new literature.
Scutellaria litwinowii Bornm. \& Sint., Lamiaceace, is one of the Iranian species of Scutellaria. In our previous study we reported that the $\mathrm{CH}_{2} \mathrm{Cl}_{2}$ fraction of the S. litwinowii extract has cytotoxic effects against human gastric adenocarcinoma (AGS), human cervix carcinoma cell line (HeLa), human breast cancer cell line (MCF-7), and rat pheochromocytoma cell line (PC12) (Tayarani-Najaran et al., 2009).

In the course of our search for anti-tumor compounds, analysis of the $\mathrm{CH}_{2} \mathrm{Cl}_{2}$ fraction obtained from $S$. litwinowii extract led to the isolation of two flavones: wogonin and neobaicalein that are cytotoxic toward HeLa cell. Details of the isolation, structural elucidation, and cytotoxic activities are described herein. The growth-inhibitory activities of neobaicalein (1) and wogonin (2) toward HeLa cells were compared with 6-hydroxyflavone (3) and baicalein (4).

\section{Materials and Methods}

\section{Chemicals}

The propidium iodide (PI) fluorescent probe, 
sodium citrate, 6-hydroxyflavone (3), baicalein (4) and triton X-100 were purchased from Sigma (St Louis, MO, USA); tetrazolium compound, 3-(4,5dimethylthiazol-2-yl)-5-(3-carboxymethoxyphenyl)-2(4-sulphophenyl)-2H-tetrazolium (MTS) from Promega (Madison, WI, USA); RPMI 1640 and FCS from Gibco (Grand Island, USA); silica gel (230-400 mesh) for column chromatography and precoated silica gel $\mathrm{GF}_{254}$ sheets from Merck (Darmstadt, Germany); methanol and distilled water as HPLC grade from Duksan (South Korea); the other solvents as analytical grade from Dr. Mojallali lab. (Tehran, Iran).

\section{Plant material}

The roots of Scutellaria litwinowii Bornm. \& Sint., Lamiaceace, were collected from Hosseinabad valley (2100 m height) in Pivejan, a village at $65 \mathrm{~km}$ south-west of Mashhad, Razavi Khorasan province, northeast of Iran. The plant was authenticated by Mr. M.R. Joharchi, Ferdowsi University of Mashhad Herbarium (FUMH). Voucher specimen (No: 14175) was deposited in herbarium of School of Pharmacy, Mashhad University of Medical Sciences (Ghahreman \& Attar, 1999).

\section{Instrumentation}

Melting points were taken in a single capillary tube on a Toshniwal melting point apparatus (Mumbai, India) and are uncorrected. NMR spectra were recorded on a Bruker Avance 500 at $25^{\circ} \mathrm{C}$ using $\mathrm{CDCl}_{3}$ as solvent and TMS as internal standard (proton and carbon frequencies were 500.13 and $125.75 \mathrm{MHz}$ respectively). Reversed-phase semi-preparative HPLC separations were carried out on a Wellchrom Knauer system (Herbert Knauer GmbH, Berlin, Germany), that consisted of a Knauer K-1001 pump, using RP18 (250 mm×16 mm, $5 \mu \mathrm{m})$ column, eluted isocratically with $\mathrm{MeOH} / \mathrm{H}_{2} \mathrm{O}$ (9:1) mixed with $0.05 \%$ phosphoric acid $\mathrm{v} / \mathrm{v}$ (adjusted by triethylamine to $\mathrm{pH} 3$ ) at $2 \mathrm{~mL} / \mathrm{min}$. Knauer K-2600 $\mathrm{UV}$-Vis detector was set at $270 \mathrm{~nm}$. The pure compounds were resuspended in DMSO and were then screened for growth inhibition of HeLa cells by MTS assay.

\section{Extraction, isolation and purification of neobaicalein and wogonin}

Dry powdered roots of $S$. litwinowii (400 g) were extracted three times with $2 \mathrm{~L}$ of methanol $90 \%$ for $24 \mathrm{~h}$ at room temperature. The combined filtered extracts were evaporated to dryness under vacuum at $50{ }^{\circ} \mathrm{C}$ to afford $25 \mathrm{~g}$ of crude methanol extract (yield 6.25\%). The residue was dissolved in $\mathrm{MeOH} / \mathrm{H}_{2} \mathrm{O}(9: 1)$ and the solution was extracted subsequently with $n$-hexane, $\mathrm{CH}_{2} \mathrm{Cl}_{2}$, ethylacetate, $n$-butanol and finally water using the partitioning method described previously (Otsuka, 2006). Then, based on the superior cytotoxic and apoptogenic properties of the $\mathrm{CH}_{2} \mathrm{Cl}_{2}$ fraction among other fractions, mentioned in our previous report (Tayarani-Najaran et al., 2009), the $\mathrm{CH}_{2} \mathrm{Cl}_{2}$ fraction (3.7 g) was selected and fractionated by silica gel column chromatography using a mixture of petroleum ether and ethyl acetate with increasing polarity to yield twelve fractions. The fractions were pooled according to TLC profiles and evaporated. Then the fractions (petroleum ether/ethyl acetate, 78:22, and 70:30) were repeatedly subjected to reversed-phase semiparaperative HPLC. This yielded 9.5 and $6.4 \mathrm{mg}$ of compounds neobaicalein (1) and wogonin (2) respectively. The structure of these compounds was determined using 1D and 2D NMR methods (Table 1).<smiles>COc1cccc(O)c1C1CC(=O)c2c(O)c(OC)c(OC)c(OC)c2O1</smiles>

1<smiles>O=c1cc(-c2ccccc2)oc2ccc(O)cc12</smiles>

3<smiles>COc1cc(O)c(O)c2c(=O)cc(-c3ccccc3)oc12</smiles>

2<smiles>O=c1cc(-c2ccccc2)oc2cc(O)c(O)c(O)c12</smiles>

4

\section{HeLa cells culture}

HeLa cells were obtained from Pasteur Institute (Tehran, Iran) and maintained at $37{ }^{\circ} \mathrm{C}$ in a humidified atmosphere $(90 \%)$ containing $5 \% \quad \mathrm{CO}_{2}$. Cells were cultured in Roswell Park Memorial Institute medium (RPMI 1640 medium) with 10\% (v/v) fetal bovine serum, $100 \mathrm{U} / \mathrm{mL}$ penicillin and $100 \mathrm{mg} / \mathrm{mL}$ streptomycin. HeLa cells were seeded overnight and then incubated with various concentrations of neobaicalein (1), wogonin (2), 6-hydroxyflavone (3), and baicalein (4) for $48 \mathrm{~h}$.

For MTS assay, cells were seeded at $5 \times 10^{3}$ cells per well onto 96-well culture plates. For assay of apoptosis, cells were seeded at $10^{4}$ cells per well onto a 24 -well plate. For each concentration and time course study, there was a control sample that remained untreated and received an equal volume of medium.

\section{Leukocyte culture}

Human umbilical cord blood samples $(50 \mathrm{~mL})$ were collected from a fresh umbilical cord attached to the placenta by gravity flow in a sterile $50 \mathrm{~mL}$ syringe 
Table 1. ${ }^{1} \mathrm{HNMR}(500.13 \mathrm{MHz})$ and ${ }^{13} \mathrm{CNMR}(125.75 \mathrm{MHz})$ data for neobaicalein (1) (Takido et al., 1975; Iinuma et al., 1979) and wogonin (2) (Li et al., 2004) in $\mathrm{CDCl}_{3}$.

\begin{tabular}{|c|c|c|c|c|}
\hline \multirow{2}{*}{ Position } & \multicolumn{2}{|c|}{ neobaicalein (1) } & \multicolumn{2}{|c|}{ wogonin (2) } \\
\hline & $\delta-{ }^{13} \mathrm{C}(\mathrm{ppm})$ & $\delta-^{1} \mathrm{H}(\mathrm{ppm}), J(\mathrm{~Hz})$ & $\delta-{ }^{13} \mathrm{C}(\mathrm{ppm})$ & $\delta-^{1} \mathrm{H}(\mathrm{ppm}), J(\mathrm{~Hz})$ \\
\hline 1 & - & - & - & - \\
\hline 2 & 162 & _- & 163.5 & _- \\
\hline 3 & 112.2 & $6.62 \mathrm{~s}$ & 105.9 & $6.68 \mathrm{~s}$ \\
\hline 4 & 183.3 & - & 182.4 & - \\
\hline 5 & 152.9 & _- & 157.7 & _ \\
\hline 6 & 136.3 & _ & 98.8 & $6.44 \mathrm{~s}$ \\
\hline 7 & 146.4 & _- & 148.8 & _ \\
\hline 8 & 132.8 & _ & 126.8 & _- \\
\hline 9 & 149.7 & _- & 155.2 & _- \\
\hline 10 & 106.8 & _ & 105.27 & _- \\
\hline $1^{\prime}$ & 108.7 & _ & 131.1 & _- \\
\hline $2^{\prime}$ & 158.8 & - & 126.2 & $7.92 \mathrm{~d}(J=6.87)$ \\
\hline $3^{\prime}$ & 102.9 & $6.66 \mathrm{~d}(J=8.5 \mathrm{~Hz})$ & 129.2 & $7.56 \mathrm{~m}$ \\
\hline $4^{\prime}$ & 132.8 & $7.28 \mathrm{t}(\mathrm{J}=8.5 \mathrm{~Hz})$ & 131.9 & $7.56 \mathrm{~m}$ \\
\hline $5^{\prime}$ & 110.1 & $6.51 \mathrm{~d}(J=8.5 \mathrm{~Hz})$ & 129.2 & $7.56 \mathrm{~m}$ \\
\hline $6^{\prime}$ & 156.4 & - & 126.2 & $7.92 \mathrm{~d}(J=6.87)$ \\
\hline $6^{\prime}-\mathrm{OCH}_{3}$ & 55.8 & $3.80 \mathrm{~s}$ & - & _- \\
\hline $6-\mathrm{OCH}_{3}$ & 61.1 & $3.92 \mathrm{~s}$ & - & - \\
\hline $7-\mathrm{OCH}_{3}$ & 61.2 & $4.10 \mathrm{~s}$ & - & - \\
\hline $8-\mathrm{OCH}_{3}$ & 62.1 & $3.91 \mathrm{~s}$ & 62.0 & $4.05 \mathrm{~s}$ \\
\hline $2 '-\mathrm{OH}$ & - & $8.23 \mathrm{~s}$ & - & - \\
\hline $5-\mathrm{OH}$ & _- & $12.23 \mathrm{~s}$ & _ & $12.48 \mathrm{~s}$ \\
\hline
\end{tabular}

containing citrate buffer as an anticoagulant. The sample was diluted with an equal volume of Phosphate Buffered Saline (PBS), then layered over Ficoll-Hypaque density gradient separation solution $(1.077 \mathrm{~g} / \mathrm{mL})$, and centrifuged at $800 \times g$ for $20 \mathrm{~min}$ at room temperature. The mononuclear cell layer was removed, washed twice in PBS and resuspended in RPMI 1640 medium supplemented with $2 \mathrm{mM}$ glutamine (Sigma Chemical Co.), antibiotics and $10 \%$ FCS. Leukocytes $\left(5 \times 10^{4}\right.$ cells per well) were incubated with various concentrations of neobaicalein (1) (1.5-100 $\mu \mathrm{M})$ in 96-well microtiter plates, for $48 \mathrm{~h}$. This study protocol was approved by the ethical committee of Mashhad University of Medical Sciences.

\section{Cell proliferation and viability assays}

The MTS assay (Malich et al., 1997), is based on the reduction, by mitochondrial dehydrogenase in metabolically active cells, of the MTS to the colored, watersoluble formazan that absorbs at $490 \mathrm{~nm}$. The cells were seeded in each well of a 96-microwell plate and treated with various concentrations of neobaicalein (1), wogonin (2), 6-hydroxyflavone (3), and baicalein (4). After $48 \mathrm{~h}$ of incubation, CellTiter $96^{\circledR} \mathrm{AQ}_{\text {ueous }}$ Assay reagent (Promega, Madison, WI, USA), which is composed of the solutions of a novel tetrazolium compound MTS and an electron coupling reagent phenazine methosulfate (PMS, a redox intermediary), was added to each well according to the manufacturer's instructions. After $1 \mathrm{~h}$, cell viability was determined by measuring the absorbance at $490 \mathrm{~nm}$ using an ELISA microplate reader (Awareness, Palm City, FL, USA).

The cytotoxicity was expressed as IC50, which was calculated using Graph Pad Software (Graph Pad prism 5 software) and presented as mean \pm SEM of three independent experiments with three replicates for each concentration.

\section{Cell morphology}

The HeLa cells were plated in 96-well plates at a density of $5 \times 10^{3}$ cells/well and grown for $24 \mathrm{~h}$ in order to attach to the surface of the plates completely. Neobaicalein (1), wogonin (2), 6-hydroxyflavone (3), and baicalein (4) were added in different concentrations $(0,25,50$ and 100 $\mu \mathrm{M})$ to the cells and then the cells were grown at $37^{\circ} \mathrm{C}$ in 
a humidified atmosphere with $5 \% \mathrm{CO}_{2}$ for $48 \mathrm{~h}$. For cell morphology experiments, the culture plates were examined and photographed by the inverted light microscope.

\section{Apoptosis}

Apoptotic cells were detected using PI staining of treated cells followed by flow cytometry to detect the socalled sub-G1 peak (Nicoletti et al., 1991; Tayarani-Najaran et al., 2010). Briefly, HeLa cells were cultured overnight in a 24-well plate and treated with various concentrations of neobaicalein (1) for $48 \mathrm{~h}$. Floating and adherent cells were then harvested and incubated at $4{ }^{\circ} \mathrm{C}$ overnight in the dark with $750 \mathrm{~mL}$ of a hypotonic buffer $(50 \mathrm{mg} / \mathrm{mL}$ PI in $0.1 \%$ sodium citrate $+0.1 \%$ Triton $\mathrm{X}-100$ ) before flow cytometric analysis using a Partec flow cytometer $(\mathrm{GmbH}$, Münster, Germany) was conducted. Ten thousand events were acquired.

\section{Statistical analysis}

One-way analysis of variance (ANOVA) and Bonferroni's post hoc were used for data analysis. All results were expressed as mean \pm SEM. $p<0.05$ was considered statistically significant. The IC50 values and their 95\% confidence intervals (CI 95\%) were obtained by nonlinear regression using the Graphpad program (Intuitive Software for Science, San Diego, CA, USA).

\section{Results}

Identification of individual chemical constituents in $\mathrm{S}$. litwinowii with growth-inhibitory activity

In our previous study we analyzed different fractions of Scutellaria litwinowii Bornm. \& Sint., Lamiaceace, root extract for their possible cytotoxic activity. Among them, the $\mathrm{CH}_{2} \mathrm{Cl}_{2}$ fraction was found to be more effective than the other fractions on human cancer cells (Tayarani-Najaran et al., 2009). To identify individual biologically active compounds within the chemically complex $\mathrm{CH}_{2} \mathrm{Cl}_{2}$ fraction of $\mathrm{S}$. litwinowii, we separated the $\mathrm{CH}_{2} \mathrm{Cl}_{2}$ fraction of $S$. litwinowii by $\mathrm{CC}$ and HPLC and screened the isolated compounds for the ability to inhibit HeLa cells growth by MTS assay.

Normal-phase column chromatography of the $\mathrm{CH}_{2} \mathrm{Cl}_{2}$ fraction of this root extract, followed by semi-preparative reversed-phase HPLC afforded two compounds. Compound 1 (neobaicalein or skullcapflavone II) was a yellow powder $(9.5 \mathrm{mg})$, with a melting point of 181-183 ${ }^{\circ} \mathrm{C}$ (Djerassi, 1994), that was obtained from petroleum ether/ethyl acetate (78:22) fraction and compound 2 was a yellow powder (6.4 mg), with a melting point of $203{ }^{\circ} \mathrm{C}$ (Djerassi, 1994), that was obtained from petroleum ether/ethyl acetate (70:30) fraction. The ${ }^{1} \mathrm{H}-\mathrm{NMR}$ and ${ }^{13} \mathrm{CNMR}$ of the isolated compounds are shown in Table 1. Based on these results and literature reports of compounds known to be in other Scutellaia spp. (Shang 2010), it was confirmed that the compounds are wogonin (mw 284, 2), and neobaicalein (mw 374, 1).

\section{Effects of neobaicalein on cell proliferation and viability of tumor cells and lymphocytes}

The cytotoxicity of neobaicalein (1) to HeLa cells was investigated using the colorimetric MTS assay. Firstly, HeLa cells were incubated with various concentrations of neobaicalein $(1.5-100 \mu \mathrm{M})$ for $48 \mathrm{~h}$. As shown in Figure 1 neobaicalein decreased cell viability of HeLa cells in a concentration-dependent manner. This toxicity was associated with morphological changes including reduction of cell volume and rounding of the cells. The substantial morphological changes observed in neobaicalein-treated HeLa cells were examined and photographed by the inverted light microscope. Damaged cells became round and shrunken, while the untreated cells retained their normal size and shape (Figure 2).

According to the MTS assay, incubation of neobaicalein in the same range of concentrations produced less toxicity to lymphocytes than HeLa cells (Figure 1).

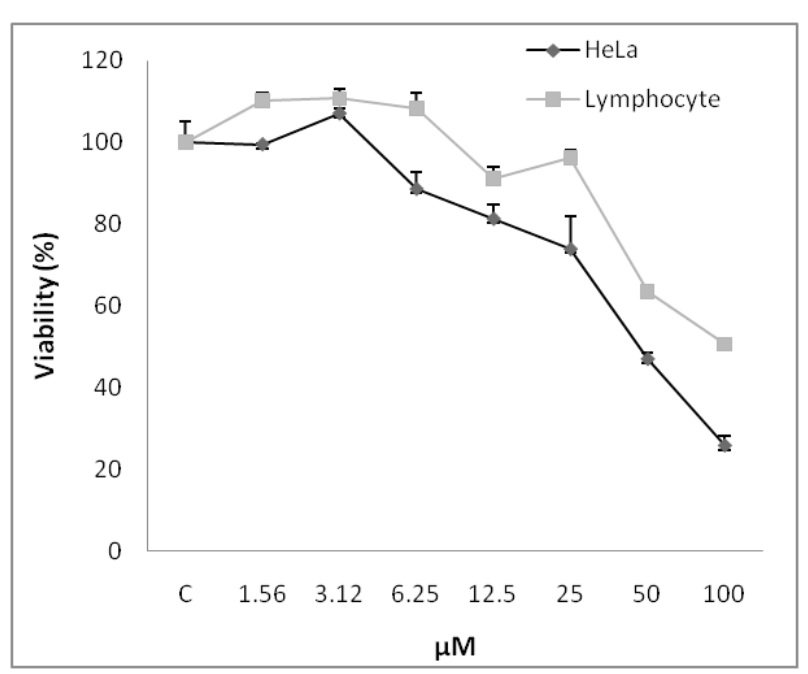

Figure 1. A. Comparison of the cytotoxic effects of neobaicalein on HeLa cells and normal proliferating lymphocytes from human umbilical cord cells. Cells were treated with different concentrations of neobaicalein for $48 \mathrm{~h}$. Neobaicalein, was less cytotoxic on normal proliferating lymphocytes. Data are representative of three independent experiments and express the mean $\pm \mathrm{SEM}$.

Comparative analysis of cell growth inhibition by neobaicalein (1), wogonin (2), 6-hydroxyflavone (3), and baicalein (4) 

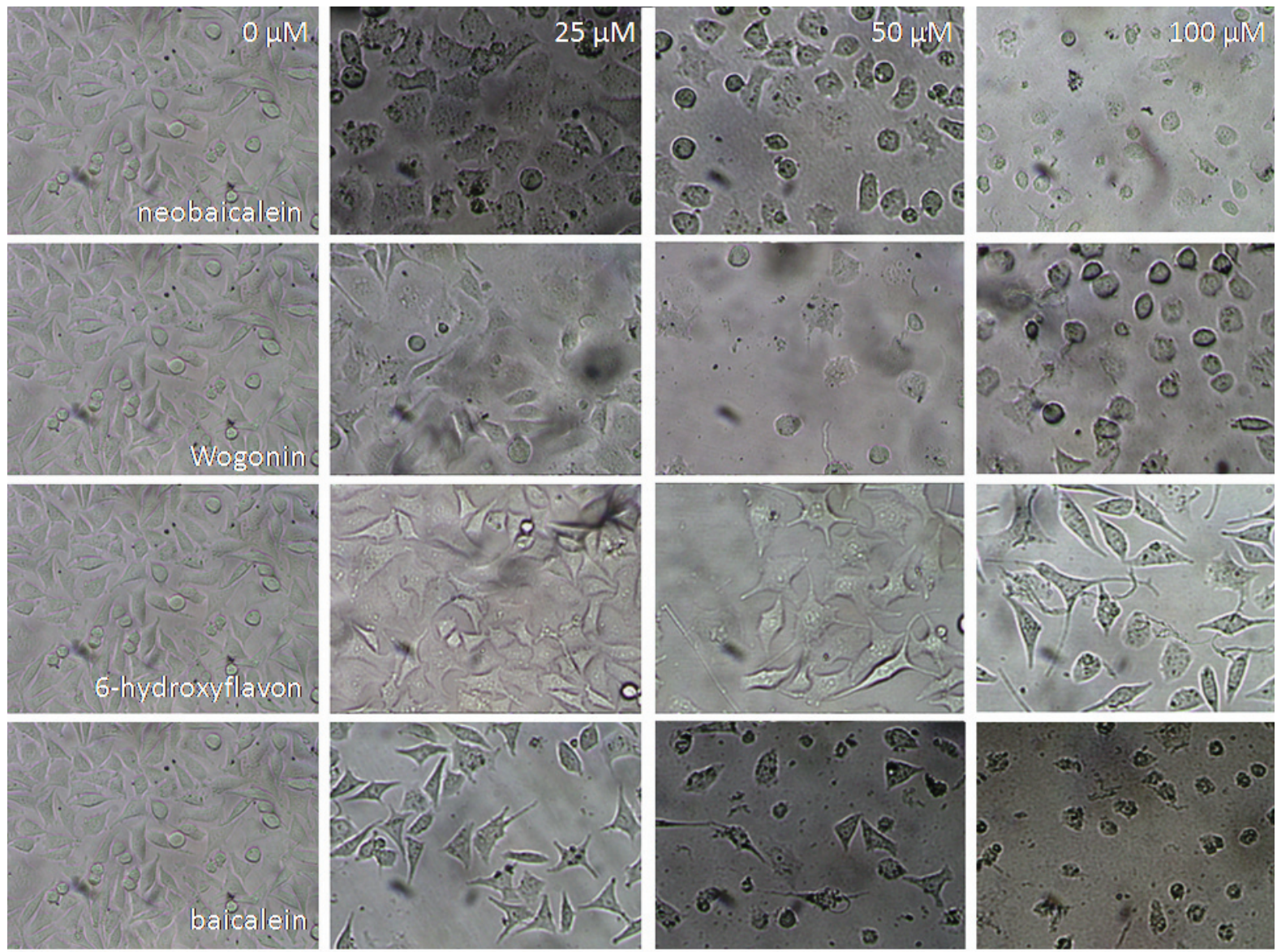

Figure 2. Morphological changes of HeLa cells after treatment with neobaicalein, wogonin, 6-hydroxyflavone, and baicalein for 48 h. Control cells remained untreated and received an equal volume of the solvent.

Cytotoxicity of neobaicalein (1), wogonin (2), 6-hydroxyflavone (3), and baicalein (4) was examined on HeLa cells. In order to compare the cytotoxicity of isolated flavonoides with 6-hydroxyflavone and baicalein against malignant cells, another MTS assay was carried out for different concentrations $(1.5-100 \mu \mathrm{M})$. Among them, neobaicalein was found to be more effective than the other compounds (Figure 2,3) and its toxicity started at a concentration as little as $6 \mu \mathrm{M}$. All the compounds showed inhibitory effects on the HeLa cells in a concentrationdependent manner. The IC50 values of all the compounds against HeLa cells after $48 \mathrm{~h}$ of treatment are shown in Table 2.

Role of apoptosis in HeLa cells treated with neobaicalein

Apoptosis following treatment with neobaicalein (1) $(6-100 \mu \mathrm{M})$ was measured with PI staining and flow cytometry, aiming to detect the sub-G1 peak resulting from DNA fragmentation. Flow cytometry histogram of the neobaicalein-treated cells exhibited a sub-G1 peak in HeLa cells which indicates the involvement of an apoptotic process in neobaicalein-induced cell death (Figure 4).

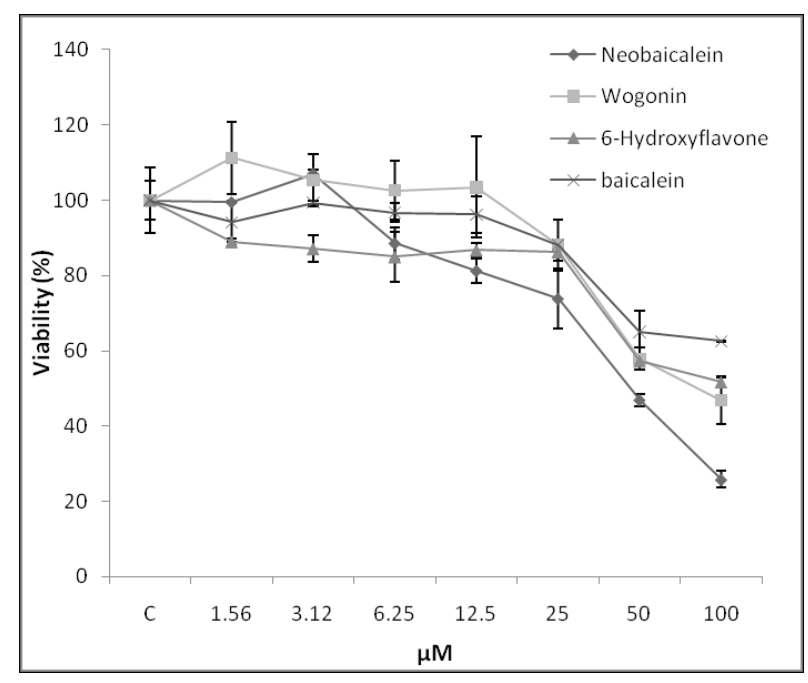

Figure 3. Effect of neobaicalein (1), wogonin (2), 6-hydroxyflavone (3), and baicalein (4) on cell viability of HeLa cells. (A) HeLa cells were treated with different concentrations of neobaicalein, wogonin, 6-hydroxyflavone, and baicalein for $48 \mathrm{~h}$. Viability was quantitated by MTS assay. Data are representative of three independent experiments and express the mean \pm SEM. 
Table 2. IC50 values of neobaicalein (1), wogonin (2), 6-hydroxyflavone (3), and baicalein (4) against HeLa cell line and lymphocytes. Data are presented as IC50 values and 95\% confidence interval (CI 95\%) from three independent experiments, performed in triplicate.

\begin{tabular}{lcccc}
\hline \multicolumn{4}{c}{ IC50 $\mu \mathrm{M}(\mathrm{CI}$ 95\%) } \\
\hline HeLa cell line & neobaicalein (1) & wogonin $(\mathbf{2})$ & 6-hydroxyflavone (3) & baicalein (4) \\
\hline Lymphocytes & 46.62 & 79.34 & $>100$ & $>100$ \\
\hline
\end{tabular}
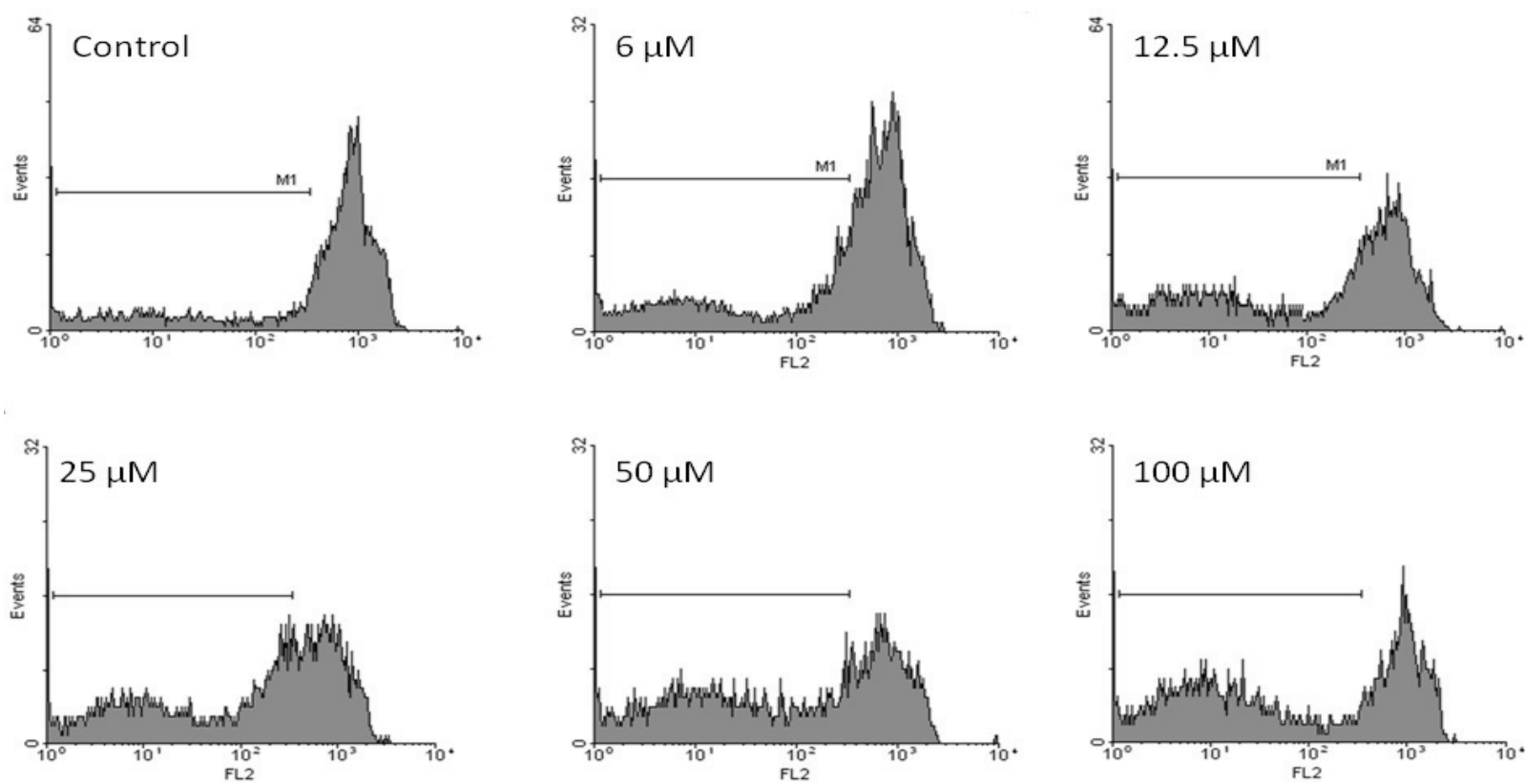

Figure 4. Role of apoptosis in neobaicalein-induced toxicity in HeLa cells. Flow cytometry histograms of PI-stained HeLa cells treated with neobaicalein for $48 \mathrm{~h}$. Sub-G1 peak as an indicative of apoptotic cells, was induced in neobaicalein-treated but not in control cells. 


\section{Discussion}

The present study was conducted to evaluate the cytotoxic activity of putative bioactive compounds found in the $\mathrm{CH}_{2} \mathrm{Cl}_{2}$ fraction of Scutellaria litwinowii Bornm. \& Sint., Lamiaceace, and to explore the potential bioactive components responsible for this cytotoxic activity.

The HPLC fractionation of $S$. litwinowii identified two flavones that were cytotoxic toward HeLa cell line: neobaicalein (1), and wogonin (2). In this study, we evaluated the active compound neobaicalein as an anticancer agent on HeLa cells for the first time and most important is that our findings revealed that apoptosis is involved in neobaicalein mediated cancer cell death. Based on the result of our previous research, the inhibition of tumor growth by the $\mathrm{CH}_{2} \mathrm{Cl}_{2}$ fraction of $S$. litwinowii may be through apoptosis. In this study, the cytotoxic and proapoptotic effects of neobaicalein on HeLa cells were investigated.

A major complication of chemotherapy is toxicity to normal cells, which is due to the inability of drugs to differentiate between normal and malignant cells. This often impacts the efficacy of treatment and even makes it impossible to cure the patients. One of the requisites of a cancer chemo-preventive agent is elimination of damaged or malignant cells through cell cycle inhibition or induction of apoptosis without or with less toxicity in normal cells (Srivastava \& Gupta, 2006). The growth inhibition assays we carried out on HeLa cells and lymphocytes treated with neobaicalein revealed differences in potency among normal and human tumor cells. A balance between therapeutic vs toxic effects is important while assessing the therapeutic potential of a given compound. In regard to chemotherapy side effects, it is essential to know whether the compound exerts a harmful effect on normally dividing cells such as proliferating lymphocytes (Anazetti et al., 2003). In this context, neobaicalein seems to be less cytotoxic toward normal cells (lymphocytes), since an increased $\mathrm{IC}_{50}$ was calculated at similar concentrations against normal cells (lymphocytes).

The growth inhibition assays we carried out on HeLa cells by neobaicalein (1), wogonin (2), 6-hydroxyflavone (3), and baicalein (4) revealed differences in potency among the four compounds. The IC50 values of 46.62 and $79.34 \mu \mathrm{M}$ were, respectively, found for neobaicalein and wogonin against HeLa cells after $48 \mathrm{~h}$ of treatment. While the IC50 values for 6-hydroxyflavone, and baicalein were more than $100 \mu \mathrm{M}$.

The apoptotic process comprises a series of events including cell shrinkage, increased cytoplasmic density, and chromatin condensation and separation into sharply bounded masses that abut the nuclear membrane and can form blister-like budding. The latter then segregate to produce membrane-bound apoptotic bodies. The integrity of the plasma membrane is preserved to the late stages of apoptosis. In contrast, necrotic cells demonstrate chromatin clumping into ill-defined masses and gross swelling of organelles. Rupture of the plasma membrane occurs later and the contents of the cytoplasm are released from the cell.

It should be notified that cell death is not always accompanied by the typical features of either apoptosis or necrosis. Examples of cell death have been described in which the pattern of morphological and/or biochemical changes neither resembled typical apoptosis nor necrosis but often had features of both. In some cases, the integrity of the plasma membrane was preserved, but DNA degradation was random, without evidence of internucleosomal cleavage. In other situations, DNA degradation was typical of apoptosis, but nuclear fragmentation and other features of apoptosis were not apparent. Generally, while most hematopoietic lineage cell types are primed to apoptosis and their death has typical features of apoptosis, the death of epithelial type cells is more complex and sometimes difficult to classify. Furthermore, some drugs which cause apoptosis may also mystify the pattern of cell death due to the drug-induced secondary effects on the cell. For example, when apoptosis is triggered by drugs affecting cell structure and function or by drugs affecting one or more pathways of the apoptotic cascade, particular features of apoptosis may not be apparent. Likewise, prolonged cell arrest in the cell cycle induced by some drugs leads to growth imbalance which may significantly alter cell biochemistry and morphology (Darzynkiewicz et al., 1997).

All four compounds share the same flavone backbone. The major differences between the chemical structures are the presence and position of hydroxyl and methoxy groups. Previous studies involving baicalein and wogonin showed that these compounds influence multiple cellular processes (Shang et al., 2010; Wakabayashi \& Yasui, 2000; Hui et al., 2002). In contrast, little is known about the activities of 6-hydroxyflavone and neobaicalein. The only growth inhibition assay that has been carried out with neobaicalein was done on the LNCaP and PC-3 cells (Bonham et al., 2005). Neobaicalein-mediated inhibition of HeLa cells growth has not been described before, although wogonin has been reported to reduce the proliferation of several cell types (Ikemoto et al., 2000; Sonoda et al., 2004) including HeLa cells (Yang et al., 2009; Yu et al., 2007).

It is considered important to screen apoptotic inducers from plants, either in the form of crude extracts or as components isolated from them. In the present study neobaicalein-induced apoptosis was involved in the induction of cell death. Apoptotic cells exhibit several biochemical modifications such as protein cleavage, protein cross-linking, DNA fragmentation, and phagocytic recognition that together result in the distinctive structural pathology (Mousavi et al., 2008). 
No previous literature has reported the possible apoptotic activity of neobaicalein in the inhibition of cancer cell growth. According to Figure 1, a concentrationdependent induction of apoptosis was detected in the neobaicalein-treated HeLa cells. It has been reported that DNA fragmentation creates small fragments of DNA that can be eluted following incubation in a hypotonic phosphate-citrate buffer. When cells are stained with a quantitative DNA-binding dye such as PI, aiming to detect the sub-G1 peak resulting from DNA fragmentation, cells that have lost DNA will take up less stain and will appear to the left of the G1 peak (Brohem et al., 2009).

Neobaicalein is a flavone with two phenolic hydroxyl and four methoxyl groups. QSAR studies of flavone have indicated that methylated flavones in general possess antiproliferative properties. It has been demonstrated that fully methylated flavones appear to have great potential as cancer chemopreventive/ chemotherapeutic agents, in particular in oral cancer (Walle et al., 2007).

Administering individual pure compounds is advantageous because it eliminates the inconsistencies involved in plant cultivation and extraction procedures and reduces the side effects that may be attributed to undesirable chemicals within the plant (Nelson \& Montgomery 2003). The results reported here indicate that most of the activities of $S$. litwinowii toward the HeLa cells that we evaluated can be recapitulated with two purified isoflavones.

Neobaicalein might be one of the potential compounds in the crude extract of S. litwinowii that could be effective in the prevention and/or treatment of cancer.

\section{Acknowledgments}

The authors would like to thank Dr. H. Nasirli for her assistance in flow cytometry. This work was supported by grants from Research Affairs of Mashhad University of Medical Sciences, the Specialized Research Fund (No. 87887) for the Pharmacy Doctoral Program. We are also grateful for the editorial assistance of Dr. N. TayaraniNajaran.

\section{References}

Anazetti MC, Melo PS, Dura'n N, Haun M 2003. Comparative cytotoxicity of dimethylamide-crotonin in the promyelocytic leukemia cell line (HL60) and human peripheral blood mononuclear cells. Toxicology 188: 261-274

Bonham M, Posakony J, Coleman I, Montgomery B, Simon J, Nelson PS 2005. Characterization of Chemical Constituents in Scutellaria baicalensis with Antiandrogenic and Growth-Inhibitory Activities toward Prostate Carcinoma. Clin Cancer Res 15: 3905-3914.
Brohem CA, Sawada TCH, Massaro RR, Almeida RL, Rivelli DP, Ropke CD, da Silva VV, de Lima TM, Curi R, Barros SBM, Maria-Engler SS 2009. Apoptosis induction by 4-nerolidylcatechol in melanoma cell lines. Toxicol In vitro 23: 111-119.

Burnett BP, Jia Q, Zhao Y, Levy RM 2007. A medicinal extract of Scutellaria baicalensis and Acacia catechu acts as a dual inhibitor of cyclooxygenase and 5- lipoxygenase to reduce inflammation. J Med Food 10: 442-451.

Darzynkiewicz Z, Juan G, Li X, Gorczyca W, Murakami T, Traganos F 1997. Cytometry in Cell Necrobiology: Analysis of Apoptosis and Accidental Cell Death (Necrosis). Cytometry 27: 1-20

Djerassi C 1994. Dictionary of natural products, $1^{\text {ste }}$, Great Britain; Cambridge: Chapman and Hall, 2: 1702 and 3: 2789.

Ghahreman A, Attar F 1999. Biodiversity of plant species in Iran Tehran, Vol. 1. Iran: Tehran University Publication, 384.

Hui KM, Huen MS, Wang HY 2002. Anxiolytic effect of wogonin, a benzodiazepine receptor ligand isolated from Scutellaria baicalensis Georgi. Biochem Pharmacol 64: 1415-1424.

Ikemoto S, Sugimura K, Yoshida N, Yasumotoa R, Wadaa S, Yamamotoa K, Kishimoto T 2000. Antitumor effects of Scutellariae Radix and its components baicalein, baicalin, and wogonin on bladder cancer cell lines. Urology 55: 951-955.

Iinuma M, Matsuura S, Kusuda K 1979. C-NMR spectral studies on poly substituted flavonoids. Chem Pharm Bull 28: 708-716.

Li BH, Jiang Y, Chen F 2004. Separation methods used for Scutellaria baicalensis active components. J Chromatogr 812: 277-290

Li-Weber M 2009. New therapeutic aspects of flavones: The anticancer properties of Scutellaria and its main active constituents Wogonin, Baicalein and Baicalin. Cancer Treat Rev 35: 57-68.

Mabberley DJ 1993, The Plant-Book, $2^{\text {nd }}$ edn. UK: Cambridge University Press, 532.

Malich G, Markovic B, Winder C 1997. The sensitivity and specificity of the MTS tetrazolium assay for detecting the in vitro cytotoxicity of 20 chemicals using human cell lines. Toxicology 124: 179-192.

Malikov VM, Yuldashev MP 2002. Phenolic compounds of plants of the Scutellaria L. genus. Distribution, structure, and properties. Chem Nat Compd 38: 358-406.

Mousavi SH, Tayarani-Najaran Z, Hersey P 2008. Apoptosis, from signaling pathways to therapeutic tools. Iran $J$ Basic Med Sci 11: 121-142.

Nelson PS, Montgomery B 2003. Unconventional therapy for prostate cancer: good, bad or questionable? Nat Rev Cancer 3: 845-858.

Nicoletti I, Migliorati G, Pagliacci MC, Grignani F, Riccardi C 1991. A rapid and simple method for measuring thymocyte apoptosis by propidium iodide staining and 
flow cytometry. J Immunol Methods 139: 271-279.

Otsuka H 2006. Purification by solvent extraction using partition coefficient. In: Sarker SD, Latif Z, Gray AL (eds). Natural Products Isolation, $2^{\text {nd }}$ edn. Totowa: New Jersey, Humana Press, 269-273.

Parajuli P, Joshee N, Rimando AM, Mittal S, Yadav AK 2009. In vitro antitumor mechanisms of various Scutellaria extracts and constituent flavonoids. Planta Med 75: 4148.

Scheck AC, Perry K, Hank NC, Clark WD 2006. Anticancer activity of extracts derived from the mature roots of Scutellaria baicalensis on human malignant brain tumor cells. BMC Complem Altern M 6: 27-36.

Shang X, He X, He X, Li M, Zhang R, Fan P, Zhang Q, Jia Z 2010. The genus Scutellaria an ethnopharmacological and phytochemical review. J Ethnopharmacol 128: 279313.

Sonoda M, Nishiyama T, MatsukawaY, Moriyasu M 2004. Cytotoxic activities of flavonoids from two Scutellaria plants in Chinese medicine. J Ethnopharmacol 91: 6568.

Srivastava JK, Gupta S 2006. Tocotrienol-rich fraction of palm oil induces cell cycle arrest and apoptosis selectively in human prostate cancer cells. Biochem Bioph Res Co 346: 447-453.

Takido M, Aimi M, Takahashi S, Yamanouchi S, Torii H 1975. [Studies on the constituents in the water extracts of crude drugs. I. On the roots of Scutellaria baicalensis Georgi (Wōgon) (1) (author's transl)]. Yakugaku Zasshi 95: 10813.

Tayarani-Najaran Z, Emami SA, Asili J, Mirzaei A, Mousavi SH 2009. Analyzing cytotoxic and apoptogenic properties of Scutellaria litwinowii root extract on cancer cell lines. Evid Based Complement Alternat Med doi:10.1093/ ecam/nep214. [Epub ahead of print]
Tayarani-Najaran Z, Mousavi SH, Asili J, Emami SA 2010. Growth-inhibitory effect of $S$. lindbergii in human cancer cell lines. Food Chem Toxicol 48: 599-604.

Walle T, Ta N, Kawamori T, Wen X, Tsuji PA, Walle UK 2007. Cancer chemopreventative properties of orally bioavailable flavonoids-Methylated versus unmethylated flavones. Biochem Pharmacol 73: 1288-1296.

Wakabayashi I, Yasui K 2000. Wogonin inhibits inducible prostaglandin E2: production in macrophages. Eur $J$ Pharmacol 406: 477-481.

Yang L, Zhang HW, Hu R, Yang Y, Qi Q, Lu N, Liu W, Chu YY, You QD, Guo QL 2009. Wogonin induces G1 phase arrest through inhibiting Cdk4 and cyclin D1 concomitant with an elevation in p21Cip1 in human cervical carcinoma HeLa cells. Biochem Cell Biol 87: 933-942

Ye F, Wang H, Jiang S, Wu J, Shao J, Cheng X, Tu Y, Zhang DY 2004. Quality evaluation of commercial extracts of Scutellaria baicalensis. Nutr Cancer 49: 217-222.

Yu J, Liu H, Lei J, Tan W, Hu X, Zou G 2007. Antitumor activity of chloroform fraction of Scutellaria barbata and its active constituents. Phytother Res 21: 817-822.

Zhang Y, Wang X, Xu Z, Liu Z, Ni Q, Chu X, Qiu M, Zhao A, Jia W 2006. Protective effect of flavonoids from Scutellaria baicalensis Georgi oncerebral ischemia injury. $J$ Ethnopharmacol 108: 355-360.

\section{*Correspondence}

Seyed Ahmad Emami

Department of Pharmacognosy, School of Pharmacy, Mashhad University of Medical Science

P.O. Box 9177948564, Mashhad, Iran

emamia@mums.ac.ir

Tel.: +9805118823255 